\title{
Human Placental Lactogen Administration in the Pregnant Rat: Acceleration of Fetal Growth
}

\author{
JAMES W. COLLINS, JR., SANDRA L. FINLEY, DANIEL MERRICK, AND EDWARD S. OGATA \\ Departments of Pediatrics, Obstetrics and Gynecology, Northwestern University Medical School and Prentice \\ Women's Hospital of Northwestern Memorial Hospital and Children's Memorial Hospital, \\ Chicago, Illinois 60611
}

\begin{abstract}
To determine whether administration of human placental lactogen (hPL) to pregnant rats during late gestation might enhance fetal growth, we implanted osmotically driven minipumps to provide $75 \mu \mathrm{g}$ h PL/24 h on day 14 of the rat's 21.5-day gestation. This substantially increased maternal and fetal plasma hPL concentrations. By day 18, hPL fetuses were significantly heavier and had larger placentas than controls. From this point until term, their rate of growth $(1.20 \mathrm{~g} / 24 \mathrm{~h})$ significantly exceeded that of controls $(0.95 \mathrm{~g} / 24 \mathrm{~h})$. Birth weights differed significantly (hPL $5.86 \pm 0.08 \mathrm{~g}$; controls $5.20 \pm 0.08 \mathrm{~g}, p<$ $0.001)$. This increase was due primarily to significant increases in the growth of the liver and carcass. Enhanced glucose availability was in part responsible for this phenomenon inasmuch as plasma glucose concentrations were significantly increased in hPL maternal rats from days $\mathbf{1 5}$ to 19. This resulted on days 18 and 19 in significantly increased plasma glucose and insulin concentrations in hPL fetuses. Fetal/maternal glucose ratios did not differ between hPL and control fetuses. Fetal hepatic glycogen concentrations were significantly increased on day 18 and 19 but were similar to controls from day 20 until birth. These observations suggest that increased maternal glucose availability with consequent stimulation of fetal insulin secretion accelerated the growth of hPL fetuses. However, maternal and fetal plasma glucose concentrations and fetal plasma insulin and hepatic glycogen concentrations on days 20 and 21 were normal, suggesting that other factors also were responsible for sustaining the accelerated fetal growth on these days. These observations and the many reports of the stimulatory effect of placental lactogen upon numerous fetal metabolic functions suggest that hPL might have directly stimulated growth. (Pediatr Res 24:663-667, 1988)
\end{abstract}

\section{Abbreviations}

hPL, human placental lactogen

Placental lactogen is important for fetal growth. During the second half of pregnancy, placental lactogen is one of several factors that counter the effect of insulin in the maternal circulation, thereby facilitating glucose and amino acid availability to the fetus (1-3). In this manner, the placental secretion of this hormone indirectly stimulates intrauterine growth. Recent ob-

Received May 23, 1988; accepted July 27, 1988.

Correspondence Edward S. Ogata, M.D., Division of Neonatology, Children's Memorial Hospital, 2300 Children's Plaza, Chicago, IL 60614.

Supported in part by grants from the NIH (1P0119070) and the Juvenile Diabetes Foundation. servations suggest that placental lactogen may also directly stimulate fetal growth. Ovine placental lactogen stimulates glycogenesis in hepatocytes of the fetal rat (4) and sheep (5) and aminoisobutyric acid uptake in diaphragmatic muscle of the fetal rat (6). It also stimulates ornithine decarboxylase activity in fetal rat liver (7) and somatomedin secretion in fetal and adult tissue (8-10). Handwerger (11) has suggested that these and other observations indicate a critical role for placental lactogen in not only indirectly but also directly stimulating normal fetal growth and development. No study, however, has addressed the possibility that excess placental lactogen might actually accelerate fetal growth.

For this reason, we determined the effect of administering hPL to maternal rats upon fetal growth, and maternal, fetal, and neonatal glucose homeostasis. Our data indicate that hPL administration in the maternal rat significantly increases fetal growth. The mechanisms for this include enhancement of maternal glucose availabiltiy and a significant but transient increase in fetal insulin secretion. These observations also allow the speculation that hPL might directly stimulate fetal growth.

\section{MATERIALS AND METHODS}

Maternal. We purchased pregnant Sprague-Dawley rats (Harlan Laboratories, Madison, WI) that weighed 180-200 g before mating. Gestation was timed to within $6 \mathrm{~h}$ of mating. We anesthetized rats on day 14 (term, 21.5 days) of gestation with ketamine $(5 \mathrm{mg} / 100 \mathrm{~g}$ body weight) and, after administration of local anesthetic ( $1 \%$ xylocaine), implanted osmotic minipumps (Alzet Corp., Palo Alto, CA) into the subcutaneous tissue of the dorsum of the neck. The minipumps were loaded with hPL supplied by the National Hormone and Pituitary Program at a concentration to deliver $75 \mu \mathrm{g}$ in $24 \mathrm{~h}$. Others had reported that this dose significantly increases maternal and fetal plasma hPL concentrations (9). Control rats received pumps filled with 154 $\mathrm{mM} \mathrm{NaCl}$. The volume infused was $12 \mu \mathrm{l} /$ day in both experimental and control animals. Rats had ad libitum access to a standard diet (Purina, St. Louis, MO) and water in a temperaturecontrolled environment with a 12-h light/dark cycle. Serial measurements of maternal weight, and plasma concentrations of glucose, insulin, glucagon, and hPL were performed from day 14 until term. Blood was obtained from the warmed cut tail tip. We used only rats with 8-13 fetuses in a litter to control for the potential effect of litter number upon intrauterine growth.

Fetal. We characterized the growth and metabolic variables of fetuses of mothers who had received hPL or $\mathrm{NaCl}$. As in previous studies, we determined wet and dry weight of liver, spleen, brain, kidneys, and carcass (skeletal muscle, bone, connective and adipose tissue, and skin) and measured plasma glucose, insulin, glucagon, and hepatic glycogen concentrations (12). For fetal blood sampling, we used the method of Girard et al. (13) in which blood is obtained from the fetus with the fetal-placental 
circulation intact. The mother was anesthetized with intraperitoneal pentobarbital $(5 \mathrm{mg} / 100 \mathrm{~g})$, and the uterus was exposed so that individual fetuses could be carefully removed without disturbing the fetal-placental circulation. The fetuses were dried and maintained at $37^{\circ} \mathrm{C}$ with a heat lamp and warm moist gauze. Blood was obtained from axillary vessels. This sampling was accomplished within 10-15 s. Maternal blood was obtained from the cut tail tip at the time of sampling from each fetus. In the previous use of this technique, we found maternal blood gas tensions, $\mathrm{pH}$, and blood pressure to be stable during the sampling period (12). Pentobarbital was used because it does not alter glucose concentrations early during anesthesia (14). Adequate blood sampling from individual fetuses could only be performed from day 18 onward. After blood sampling, the fetuses were killed by decapitation and the organs quickly removed and frozen with liquid nitrogen and stored at $-70^{\circ} \mathrm{C}$. We sampled from only 2-3 fetuses in a litter to avoid any potential effect of prolonged maternal anesthesia. Each point represents data from at least 30 fetuses. Fifteen to 20 litters are represented in each group for each day of gestation.

Neonatal. On day 21.5 , we delivered rat pups by cesarean section after stunning and cervical dislocation of the mother. Pups were quickly dried, separated from their placentas, and placed in chambers which provided humidified room air at $37^{\circ}$ C. As in previous studies, we sampled blood from individual littermates to determine sequential changes in plasma glucose, insulin, and glucagon concentrations at birth and at 20,60, 120, and $240 \mathrm{~min}$ of life (15). Blood was collected from severed axillary vessels. After blood sampling, the pups were decapitated and their livers obtained for determination of sequential glycogen concentrations. Data for each metabolic variable are from at least 25 pups at each point. A minimum of 20 litters is represented in each group.

Analyses. We have reported the details of our analytical techniques (16). In brief, we determined plasma glucose concentrations with an automated analyzer (Beckman II). Blood for hormone analysis for each fetus and pup was treated with Aprotinin (Trasylol 25:1 vol/vol), and the plasma was frozen at $-70^{\circ} \mathrm{C}$. Plasma glucose and hormone concentrations were determined for each fetus. Plasma insulin and glucagon concentrations were determined with double antibody radioimmunoassays with hu- man insulin and porcine glucagon as standards $(12,13)$. Plasma samples of $25 \mu \mathrm{l}$ were used for each insulin and 50- $\mu$ l samples for each glucagon determination. For the insulin assay, the minimal detectable mass was $0.78 \mu \mathrm{U} /$ tube; for glucagon it was $7.7 \pm 2.0 \mathrm{pg} /$ tube. We modified a double antibody ${ }^{125}$ I-radioimmunoassay (Corning Immunophase, Medfield, MA) by diluting the antibody $(1: 4 \mathrm{v} / \mathrm{v})$ and tracer $(1: 5 \mathrm{v} / \mathrm{v})$ solutions with standard borate buffer. This allowed determination of individual hPL values in $50-\mu \mathrm{l}$ aliquots of standard and plasma samples in the concentration range of the fetuses and mothers in this study. In preliminary studies, we added hPL to adult male rat plasma and determined hPL concentrations in 50- $\mu$ l aliquots. Measurement of hPL at $50,100,150$, and $200 \mathrm{ng} / \mathrm{ml}$ concentrations were comparable to values for hPL in standard assay solution. When hPL was added to plasma from pregnant rats, measured values were 15 to $25 \mathrm{ng} / \mathrm{ml}$ were than expected. This assay is sensitive to $10.0 \mathrm{pg} / \mathrm{ml}$. Hepatic glycogen concentrations and tissue DNA and protein concentrations were determined as established in our laboratory.

Statistical analysis was performed using the Student's unpaired $t$ test to determine differences between groups. This protocol was approved by the animal Care Committee of Northwestern University.

\section{RESULTS}

Maternal. Implantation of hPL-loaded pumps on day 14 significantly increased maternal hPL concentrations by day 15 . Maternal plasma concentrations from day 15 to 21 were 250.2 $\pm 22.5,265.1 \pm 23.8,249.8 \pm 30.1,255.6 \pm 20.9,263.8 \pm 23.6$, $270.1 \pm 30.3$, and $260.5 \pm 25.7 \mathrm{ng} / \mathrm{ml}$. On days $18-21$, fetal plasam concentrations were $120.2 \pm 18.3,107.9 \pm 13.9,133.0$ \pm 23.5 , and $130.1 \pm 20.9 \mathrm{ng} / \mathrm{ml}$, respectively. The assay also detected hPL radioimmunoactivity of 11 to $25 \mathrm{ng} / \mathrm{ml}$ in control mothers from day 15 to 21 and in hPL mothers immediately after pump implantation on day 14.

The elevation in maternal hPL concentrations was associated with a significant increase in maternal plasma glucose concentrations. From day 15 to 19 , maternal plasma glucose concentrations significantly exceeded those of controls (Fig. 1). On days 20 and 21, plasma glucose concentrations did not differ between

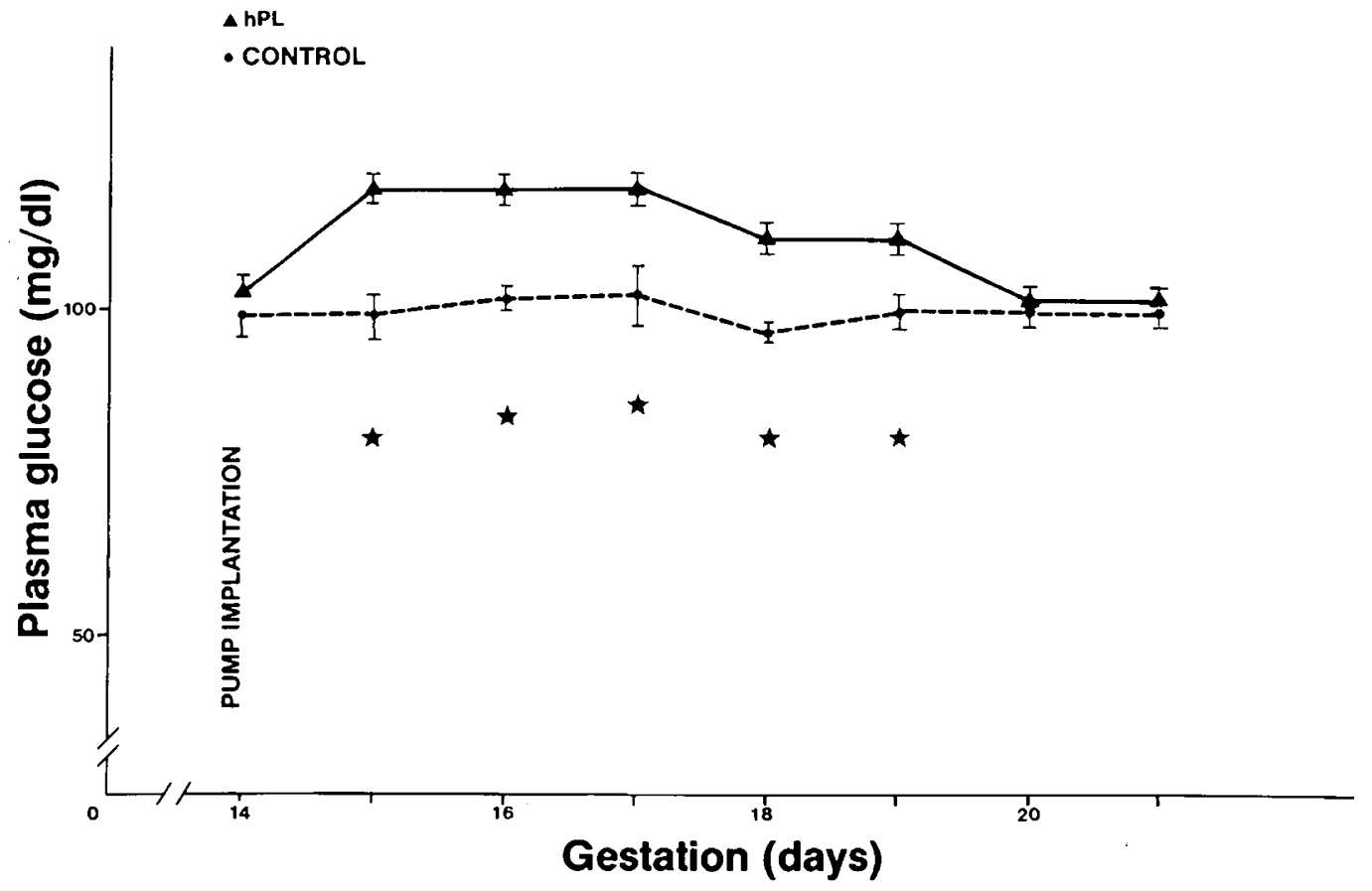

Fig. 1. Maternal plasma glucose concentrations in rats that received hPL and in controls. Plasma glucose concentrations in hPL rats significantly exceeded those of controls from days 15 to $19(p<0.001)$. 
hPL and control mothers. Maternal plasma insulin (day 18; hPL $80.5 \pm 15.1 \mu \mathrm{U} / \mathrm{ml}$; control $90.3 \pm 16.1 \mu \mathrm{U} / \mathrm{ml}$ ) and glucagon (day 18: hPL $171.0 \pm 32.0 \mathrm{pg} / \mathrm{ml}$; control $185.5 \pm 38.3 \mathrm{pg} / \mathrm{ml}$ ) concentrations did not differ between groups on days 15 to 21 . Maternal weight gain expressed in either absolute or fractional increase did not differ between hPL and control maternal rats. Body weights ranged from $180-200 \mathrm{~g}$ on day 18 to $240-270 \mathrm{~g}$ on day 21.5 .

Fetal. In hPL fetuses, plasma glucose concentrations were significantly elevated on days 18 and 19 and were similar to controls on days 20 and 21 (Fig. 2). Fetal/maternal glucose ratios

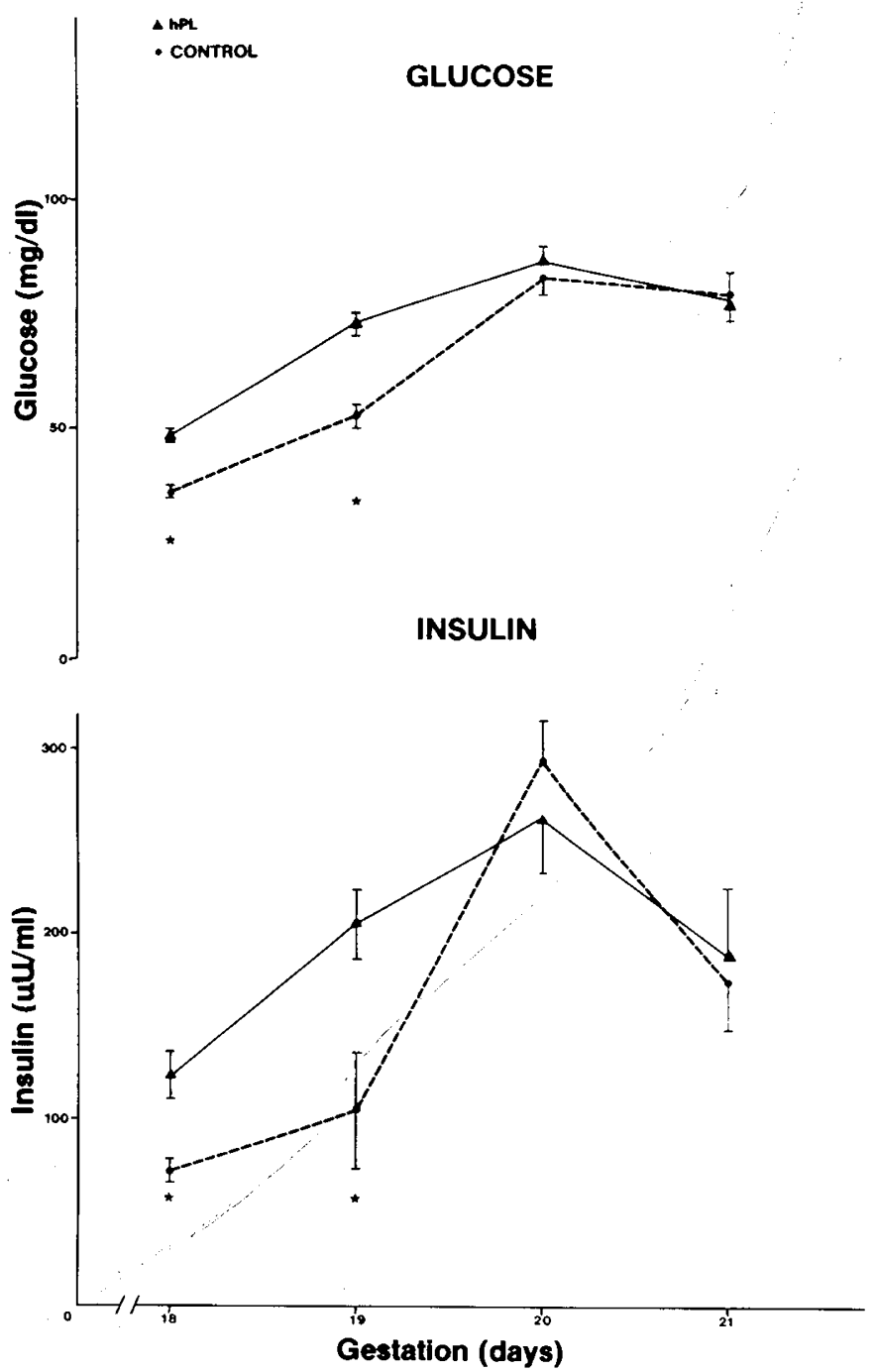

Fig. 2. Fetal plasma glucose and insulin concentrations. Fetuses of mothers that received hPL had significantly elevated plasma glucose and insulin concentrations compared to fetuses of control mothers on days 18 and $19(p<0.01$ to 0.001$)$. No differences in either variable were apparent on days 20 and 21 . were similar in hPL and control animals from days 19 to 21 (Table 1). Plasma insulin concentrations were significantly elevated in hPL fetuses on days 18 and 19 and were comparable to control values on days 20 and 21 (Fig. 2). Plasma glucagon concentrations were similar in both groups on each day of gestation (day 18; hPL $280.8 \pm 30.1 \mathrm{pg} / \mathrm{ml}$; control $301.5 \pm 40.0$ $\mathrm{pg} / \mathrm{ml}$ ). Fetal hepatic glycogen concentrations were significantly elevated in hPL fetuses on days 18 and 19 and were similar to controls thereafter (Table 1).

From day 19 until term, the body mass of hPL fetuses significantly exceeded that of controls (Fig. 3). Growth rates differed significantly between hPL $(1.20 \pm 0.09 \mathrm{~g} / 24 \mathrm{~h})$ and control $(0.95$ $\pm 0.08 \mathrm{~g} / 24 \mathrm{~h}, p<0.01$ ) fetuses. Newborn hPL pups weighed $5.86 \pm 0.08 \mathrm{~g}$ and controls, $5.20 \pm 0.08 \mathrm{~g}, p<0.001)$. The increased mass of hPL fetuses was due in great part to significant increases in carcass and liver. The rate of growth of these organs was increased proportional to overall body mass from day 19 until term. Values for carcass mass of hPL fetuses from days 19 to 21.5 were $2.78 \pm 0.04,3.90 \pm 0.03,4.93 \pm 0.04$, and $4.99 \pm$ $0.05 \mathrm{~g}$. For control fetuses, values were $2.30 \pm 0.04,3.20 \pm 0.04$, $4.09 \pm 0.04$, and $4.16 \pm 0.05 \mathrm{~g}$. Liver mass values for hPL fetuses were $0.273 \pm 0.003,0.308 \pm 0.003,0.439 \pm 0.003$, and $0.451 \pm$ $0.004 \mathrm{~g}$. Values for control fetuses were $0.258 \pm 0.004,0.278 \pm$ $0.005,0.388 \pm 0.005$, and $0.400 \pm 0.003 \mathrm{~g}$. All values differed between hPL and control groups at $p<0.01$ to 0.001 . We found that bone mass was a small fraction of carcass mass and did not differ between hPL and control fetuses and pups. While we did not measure adipose content, we observed no fat in either hPL or control carcass samples. The mass of brain, kidney, spleen, and gastrointestinal tract did not differ significantly between groups on any day of gestation. Comparison of wet and dried tissue indicated that water comprised 75 to $80 \%$ of fetal body mass in both hPL and control groups. Placental mass also significantly exceeded that of controls from day 19 until term (mass at birth hPL $0.816 \pm 0.020 \mathrm{~g}$; control $0.578 \pm 0.030 \mathrm{~g}, p$ $<0.01$ ). The increase in placental growth paralleled that of the body in hPL rats.

Neonatal. The hPL pups had plasma glucose, insulin, and glucagon values which were similar to controls during the first 240 min of life. Both groups demonstrated similar decreases in hepatic glycogen concentrations during this period. Values for hPL pups decreased from $65.5 \pm 7.3 \mathrm{mg} / \mathrm{g}$ liver at birth to 15.1 $\pm 3.2 \mathrm{mg} / \mathrm{g}$ liver at $240 \mathrm{~min}$. The sequential pattern of change for all of these variables was identical to that of normal newborn rat pups reported for other studies from our laboratory (16).

\section{DISCUSSION}

These data indicate that hPL administered in high doses to the normal pregnant rat receiving an unrestricted diet accelerates fetal growth. While the stimulatory effect of placental lactogen upon a number of metabolic processes in the fetus have been delineated, this is the first observation of an actual increased rate of fetal growth in association with maternal hPL administration. The mechanisms for this phenomenon include enhanced maternal glucose availability to the fetus and a transient increase in fetal insulin secretion. These studies also suggest that hPL may directly stimulate fetal growth.

Table 1. Fetal metabolic variables

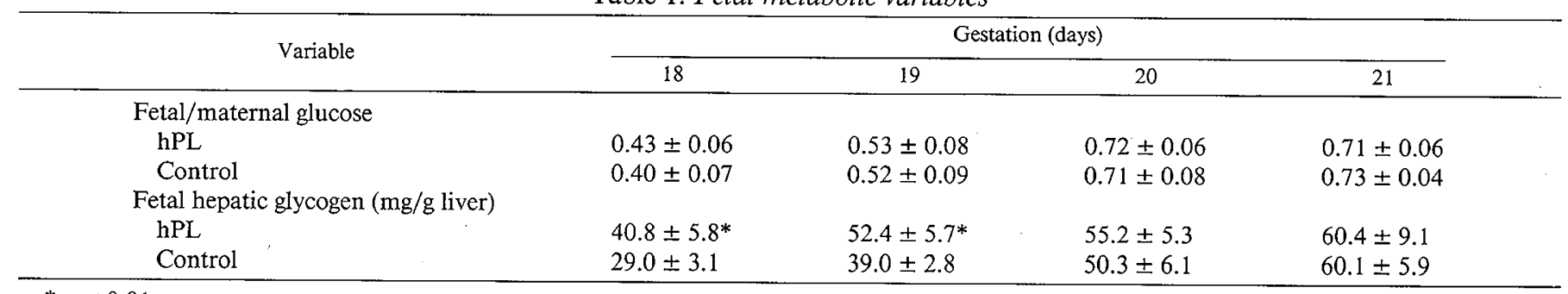

$* p<0.01$. 


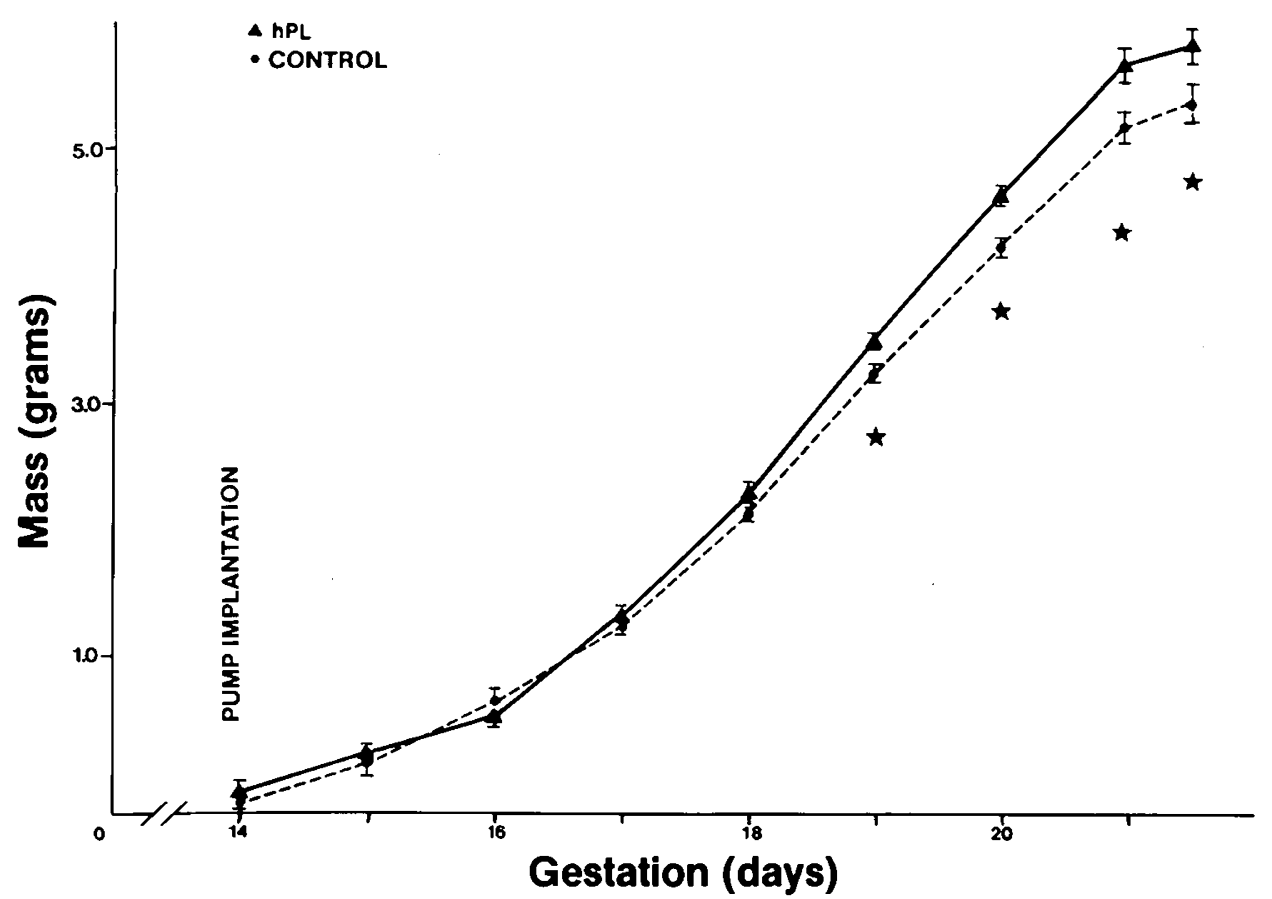

Fig. 3. Intrauterine growth of fetuses of mothers who received hPL and controls. From day 19 until term, the growth of hPL fetuses significantly exceeded that of controls $(p<0.01$ to 0.001$)$.

The mechanisms by which placental lactogen affects fetal growth under normal circumstances have been well characterized. Placental lactogen and the other hormones of pregnancy reduce maternal tissue sensitivity to insulin, limit pancreatic beta cell response to secretogogues, and enhance lipolysis $(1-3,15)$. These metabolic adjustments of normal pregnancy enhance fuel availability to the fetus, thereby indirectly facilitating fetal growth. Providing hPL to the maternal rats significantly elevated maternal and fetal plasma glucose concentrations. This hyperglycemia did not substantially alter maternal plasma insulin and glucagon concentrations, suggesting that the effect of hPL upon maternal glucose may also have been mediated through a reduction in islet cell secretory response and an increase in tissue resistance to insulin. It is unclear why this hyperglycemia was not sustained beyond day 19. Perhaps maternal tissue resistance to insulin due to hPL was decreased from this point until term.

On days 18 and 19 , the elevations in plasma glucose concentrations in hPL mothers was associated with significantly increased glucose values in their fetuses. Fetal/maternal ratios of plasma glucose concentrations did not differ between hPL and control animals, whereas plasma insulin concentrations were significantly increased in hPL fetuses. These static measurements indicate that increased provision of maternal glucose rather than enhanced endogenous production increased plasma glucose concentrations in fetuses of mothers who received hPL. The stimulation of fetal insulin secretion may have resulted from this increased glucose availability or direct stimulation of the fetal beta cell by hPL. It is possible that glucose provision to the fetus was also increased from days 15 to 18 , and this may have been important for accelerating fetal growth. Administration of hPL might also have enhanced maternal amino acid availability, which would have stimulated fetal growth.

The increased glucose and insulin availability probably contributed to the accelerated growth of hPL fetuses on days 18 and 19. Insulin is a major growth-stimulating hormone for specific insulin sensitive tissues during perinatal life $(3,17)$. The combination of excess glucose and insulin probably stimulated the growth of liver and muscle. Gross brain growth was not affected, which is consistent with observations that insulin does not stimulate the growth of neural tissue. Because we were unable to sample blood adequately from fetuses before day 18 , we can only speculate as to whether these mechanisms were acting upon fetal growth earlier during gestation. The return to control values of fetal plasma insulin concentrations on day 20 and 21 indicate an appropriate fetal $\beta$-cell response to the normal maternal and fetal plasma glucose concentrations on these days. Plasma glucagon concentrations did not change with alterations in fetal plasma glucose concentrations on days 18 and 19 , confirming the relative "immaturity" of fetal $\alpha$-cell function (18).

Large for gestational age human and rat neonates generally develop hypoglycemia on the basis of transient hyperinsulinemia (19) or other mechanisms (20). The newborn pups of hPL-treated mothers had normal glucose homeostasis. This suggests that hPL, while stimulating fetal growth, does not alter the development of glucoregulatory mechanisms as in other models of accelerated intrauterine growth (21-23).

hPL administered to the mother appeared in fetal plasma in substantial quantities and was relatively constant in both maternal and fetal plasma. The plasma concentrations attained are similar to those of another study which first described the transplacental passage of hPL in the rat (9). The radioimmunoassay used in this study detected hPL activity in the plasma of control maternal rats and excess hPL in the plasma of pregnant rats to which known amounts of hPL had been added. This indicates cross-reactivity with other substances as prolactin or related substances. Others have observed this phenomenon (9).

hPL might have directly influenced the sustained rate of accelerated growth in the hPL fetuses. Fetal plasma insulin concentrations were normal on days 20 and 21 , as demonstrated by hepatic glycogen concentrations which were in the control range. Newborn hPL pups also demonstrated normal insulin secretion after birth. Despite this reduction of insulin availability after day 20 , hPL fetuses continued to grow at the same increased rate between days 20 and 21 as between days 19 and 20. This sustained rate of increased growth and the elevation of fetal plasma hPL concentrations when insulin concentrations were normal suggest that factors other than insulin, as hPL, might have stimulated growth. hPL also in some manner stimulated placental growth. When insulin is injected into fetal rats in utero to stimulate their growth, placental growth is unaffected (21-23). Our data indicate that hPL, unlike insulin, increases placental growth in association with fetal growth. We speculate that the 
increase in placental mass might also have increased rat placental lactogen production. This could have been another factor responsible for stimulating fetal growth.

Considerable data suggest that placental lactogen directly stimulates a number of fetal metabolic functions and may thereby facilitate intrauterine growth. Ovine placental lactogen stimulates numerous anabolic processes, including enzyme induction in fetal tissues of the rat and sheep (4-8). Human placental lactogen also stimulates protein synthesis in human fetal fibroblasts (24). The role of hPL in stimulating fetal growth is strengthened by observations that the hepatic placental lactogen receptor predominates during fetal life, whereas growth hormone receptors appear and increase during postnatal life (25). However, this does not confirm a direct role of placental lactogen upon growth. It is possible that hPL may act upon growth through binding to growth hormone or prolactin receptors.

Fetal hepatic glycogen concentrations were significantly increased on days 18 and 19 in hPL fetuses; after day 19, values did not differ from controls. The increased hepatic glycogen concentrations probably resulted from the increased glucose and fetal insulin availability on these days. It is possible that hPL may have directly stimulated glycogen synthesis; however, in vitro data indicate that hPL may not stimulate glycogenesis in the fetal rat (4). If valid, this would confirm the primary role of insulin in fetal glycogenesis and explain why hepatic glycogen concentrations in hPL fetuses were not elevated after day 19. From that point on, insulin concentrations were normal despite sustained elevations of hPL concentrations.

The action of placental lactogen upon tissue growth may be direct or mediated through stimulation of the somatomedins or insulin-like growth factors. In the adult rat, hypophysectomy significantly reduces plasma somatomedin concentrations, and exogenous placental lactogen restores them (8). Pregnant rats restricted in protein intake have low placental and serum concentrations of rat placental lactogen. Plasma somatomedin concentrations are correspondingly depressed $(26,27)$. Insulin-like growth factor II is decreased in fetal rats whose growth is limited by maternal protein-calorie deprivation. Administration of hPL to the mother, which substantially increases fetal plasma hPL concentrations, restores fetal insulin-like growth factor II (9).

While our observations and other studies suggest that placental lactogen may function as a "fetal growth hormone," numerous questions remain to be answered before this possibility can be confirmed. A dose-response relation between hPL and growth must be generated. Species differences must also be considered. The administration of placental lactogen of one species to another may result in different effects upon the same metabolic function. Whether or not hPL binds to rat placental lactogen receptors has yet to be determined. Because rat placental lactogen is presently unavailable, its effect upon fetal rat growth remains to be assessed. Whether or not limiting placental lactogen retards fetal growth must also be determined. Such homologous experiments are necessary to confirm placental lactogen's role in fetal growth. In addition, the ontogeny of placental lactogen must be defined. It has recently been reported that the fetal rat has two forms of placental lactogen which are synthesized at different points in gestation (28). Our model of hPL administration to the fetal rat may be useful in addressing these questions.

\section{REFERENCES}

1. Grumbach MM, Kaplan SL, Sciarra JJ, Burr IM 1968 Chorionic growth hormone-prolactin: secretion, disposition, biologic activity in man, and postulated function as the "growth hormone" of the second half of pregnancy. Ann NY Acad Sci 148:501-512

2. Friesen HG 1974 Placental protein hormones and tissue receptors for hormones. In: Gluck L (ed) Modern Perinatal Medicine. Yearbook Medical Publishers, Chicago, 224-243

3. Freinkel $N 1980$ Of pregnancy and progeny. Diabetes 29:1023-1035

4. Freemark M, Handwerger S 1984 Ovine placental lactogen stimulates glycogen synthesis in fetal rat hepatocytes. Am J Physiol 246:E21-E24

5. Freemark M, Handwerger S 1986 The glycogenic effects of placental lactogen and growth hormone in ovine fetal liver are mediated through binding to specific fetal ovine placental lactogen receptors. Endocrinology 118:613-618

6. Freemark M, Handwerger S 1983 Ovine placental lactogen, but not growth hormone, stimulates amino acid transport in fetal rat diaphragm. Endocrinology 112:402-404

7. Hurley TW, Kuhn CM, Schanberg SM, Handwerger S 1980 Differential effects of placental lactogen, growth hormone, and prolactin on rat liver ornithine decarboxylase activity in the perinatal period. Life Sci 27:2269-2275

8. Hurley TW, D'Ercole AJ, Handwerger S, Underwood LE, Furlanetto EW, Fellows RE 1977 Ovine placental lactogen induces somatomedin: a possible role in fetal growth. Endocrinology 101:1635-1638

9. Pilistine SJ, Moses AC, Munro HN 1984 Placental lactogen administration reverses the effect of low protein diet on maternal and fetal serum somatomedin levels in the pregnant rat. Proc Natl Acad Sci USA 81:5853-5857

10. Adams SO, Nissley SP, Handwerger S, Rechler MM 1983 Developmental patterns of insulin-like growth factors I and II: synthesis and regulation in rat fibroblasts. Nature 302:150-152

11. Handwerger S 1988 Human placental lactogen and fetal growth. Growth Genet Horm 4:4-6

12. Ogata ES, Bussey M, LaBarbera A, Finely S 1985 Altered growth, hypoglycemia, hypoalaninemia and ketonemia in the rat: postnatal consequences of intrauterine growth retardation. Pediatr Res 19:32-37

13. Girard JR, Ferre P, Gilbert M, Kervran A, Assan R, Marliss EB 1977 Fetal metabolic response to maternal fasting in the rat. Am J Physiol 232:E456$\mathrm{E} 462$

14. Brunner EA, Cheny SC, Berman NC 1975 Effects of anesthesia on intermediary metabolism. In: Creyer WP, Coggins CH, Hancock EW (eds) Annual Review of Medicine. Selected Topics in the Clinical Sciences 26:391-401

15. Gaspard UJ, Luyckz AS, George AN, LeFevre PJ 1977 Relationship between plasma free fatty acid levels and human placental lactogen secretion in late pregnancy. J Clin Endocrinol Metab 45:246-253

16. Bussey M, Finley S, LaBarbera A, Ogata ES 1985 Hypoglycemia in the newborn growth-retarded rat: delayed phosphoenolpyruvate carboxykinase induction despite increased glucagon availability. Pediatr Res 19:363-367

17. Hill DJ, Milner RDG 1985 Insulin as a growth factor. Pediatr Res 19:879-886

18. Girard J, Kervran A, Soufflet E, Assan R 1974 Factors affecting the secretion of insulin and glucagon by the rat fetus. Diabetes 23:310-317

19. Ogata ES, Freinkel N, Matzger BE, Phelps RL, Depp R 1980 Perinatal islet function in gestational diabetes: assessment by cord plasma C-peptide and amniotic fluid insulin. Diabetes Care 3:425-429

20. Kliegman R, Gross T, Morton S, Dunnington R 1984 Intrauterine growth and postnatal fasting metabolism in infants of obese mothers. J Pediatr 104:601607

21. Angervall L, Karlson K, Martinson A 1981 Effect on rat fetuses of intrauterine injections of insulin. Diabetologia 20:558-562

22. Catlin E, Cha CM, Oh W 1985 Postnatal growth and fatty acid synthesis in overgrown rat pups induced by fetal hyperinsulinemia. Metabolism 34:11101114

23. Ogata ES, Collins JW, Finley S 1988 Insulin injection in the rat: accelerated intrauterine growth and altered fetal and neonatal homeostasis. Metabolism 37:649-655

24. Hill DJ, Crace CJ, Strain AJ, Milner RDG 1986 Regulation of amino acid uptake and deoxyribonucleic acid synthesis in isolated human fetal fibroblasts and myoblasts: effect of human placental lactogen, somatomedin C, multiplication-stimulating activity, and insulin. J Clin Endocrinol Metab 62:753-760

25. Freemark M, Comer M, Handwerger S 1986 Placental lactogen and GH receptors in sheep liver: striking differences in ontogeny and function. Am J Physiol 251:E328-E333

26. Wunderlich S, Surendra Baliga B, Munro H 1979 Rat placental synthesis and peptide hormone secretion in relation to malnutrition from protein deficiency or alcohol administration. J Nutr 109:1534-1541

27. Pilistine SJ, Munro HN 1984 Protein deficiency in pregnant rats causes decreased levels of plasma somatomedin and its carrier protein associated with reduced plasma levels of placental lactogen and hepatic lactogenic receptor number. J Nutr 114:638-642

28. Robertson MC, Gillespie B, Friesen HG 1982 Characterization of the two forms of rat placental lactogen (rPL): rPL-1 and rPL II. Endocrinology 111:1862-1866 